\title{
EXTRATO DE PRÓPOLIS NA NUTRIÇÃO DE CÃES: EFEITOS NA CONDIÇÃO CORPORAL, PARÂMETROS SANGUÍNEOS E RESPOSTA VACINAL
}

\author{
(Propolis extract on dog nutrition: efects on body condition, blood parameters and \\ vaccine response)
}

Nancy Montaño Rivera ${ }^{1}$, Tabyta Tamara Sabchuk ${ }^{1}$, Larissa Wünsche Risolia ${ }^{1}$, Ananda Portella Félix ${ }^{1}$, Claudio Scapinello ${ }^{2}$, Simone Gisele de Oliveira ${ }^{1}$, Alex Maiorka ${ }^{1}$

1Universidade Federal do Paraná, ²Universidade Estadual de Maringá.

*Correspondência: sgoliveira@ufpr.br

RESUMO: A própolis tem um grande potencial de utilização pelos seus efeitos como substância antimicrobiana, anti-inflamatória, antioxidante, imuno estimulante e de controle de peso. Estas características são atribuídas aos componentes flavonoides e ácidos fenólicos. Dessa forma, o objetivo do presente estudo foi avaliar o efeito da inclusão na dieta de extrato de própolis (EP) na condição corporal, parâmetros sanguíneos e resposta vacinal de cães adultos. Para avaliação da condição corporal, foram utilizados os pesos $(\mathrm{kg})$ e espessura do tecido subcutâneo $(\mathrm{mm})$ medido na vertebra $\mathrm{L} 7$, utilizando ultrassonografia. Foi coletado sangue dos animais no início e final do experimento e realizado análise de parâmetros sanguíneos e bioquímicos. A resposta vacinal foi avaliada contra a cinomose canina por meio do método de inibição da hemaglutinação. As características das fezes foram avaliadas pelo escore fecal. O fornecimento da dieta EP durante cinco meses estimulou a redução $(\mathrm{P}<0,05)$ de peso e de tecido adiposo subcutâneo lombar dos cães. Além de reduzir o colesterol total dos animais $(P<0,05)$. No entanto, não foram observados efeitos $(P>0,05)$ no hemograma, triglicerol, resposta vacinal e características fecais destes animais. Sendo assim, a inclusão de extrato de própolis na dieta para cães é viável e benéfica, especialmente em animais que apresentem necessidade de controle de peso corporal e de níveis de colesterol.

Palavras-chave: colesterol; gordura corporal; nutrição de cães; parâmetros sanguíneos; própolis

ABSTRACT: Propolis has great potential for use by its effects as antimicrobial substance, anti-inflammatory, antioxidant, immune stimulant and in weight control. These characteristics are attributed to its components flavonoids and phenolic acids. Taking this fact into consideration, the aim of this study was to evaluate the effect of adding the propolis extract diet (EP) on body condition, blood parameters and vaccine response of adult dogs. To evaluate the body condition, the weights were used $(\mathrm{kg})$ and thickness of the subcutaneous tissue $(\mathrm{mm})$ measured on the vertebra L7 using ultrasound. Animal blood was collected at the beginning and end of the experiment and carried out analysis of blood and biochemical parameters. A vaccine response was evaluated against canine distemper by the hemagglutination method. The stool characteristics were evaluated by fecal score. The provision of EP diet for five months promoted weight reduction $(P<0.05)$ and lumbar subcutaneous adipose tissue reduction in dogs. Besides, it reduced the total cholesterol in animals ( $P$ 
<0.05). However, no effects were observed $(P>0.05)$ in the blood count, triacylglycerol, vaccine response and fecal characteristics of these animals. Therefore, it is concluded that the inclusion of propolis extract in pet diet is viable and beneficial, particularly in animals showing need to control body weight and cholesterol levels.

Key Words: body fat; blood parameters; cholesterol; dogs nutrition; propolis

\section{INTRODUÇÃO}

A própolis é uma substância resinosa e balsâmica, que possui coloração e consistência diversas, variando de marrom ao verde escuro. É produzida pelas abelhas, que utilizam substratos extraídos de diversas partes das plantas, como brotos, botões florais e exsudatos resinosos, sendo transportados para dentro da colmeia, contribuindo para o fechamento das frestas, e reduzindo a entrada de ventos frios e ataque de inimigos naturais, como fungos e bactérias (MARCUCCI, 1999).

A própolis tem sido muito utilizada na terapia humana, pelos seus potenciais efeitos como substância antimicrobiana, anti-inflamatória, antioxidante e imuno estimulante (MORALES, 2000). Além disso, aparentemente reduzem o peso e a gordura corporal podendo ser utilizado no tratamento da obesidade (LIN; LINSHIAU, 2006). Esses efeitos terapêuticos têm sido atribuídos aos dois grandes grupos de compostos fenólicos que compõem a própolis: os flavonoides, aos quais são considerados como um dos principais compostos e os ácidos fenólicos (MORALES, 2000).

A nutrição de animais de companhia acompanha a tendência observada na nutrição humana, desta forma o extrato de própolis poderia ser utilizado na nutrição de cães. Sendo assim, a alimentação para animais de companhia visa promover uma nutrição ideal, além de fornecer boa qualidade de vida com longevidade.
Os animais de estimação dos grandes centros urbanos vivem cada vez mais confinados em pequenos espaços e normalmente tem uma vida sedentária. A conjunção de três fatores: castração, disponibilidade alta de alimentos e manejo inadequado do proprietário aumenta o aparecimento da obesidade (LAFLAMME et al., 1998; BORGES, 2004). Desta forma, há necessidade de formulas que possibilitem controlar e/ou prevenir o sobrepeso e a obesidade.

$\mathrm{Na}$ literatura consultada, não foram encontradas informações sobre o uso de extrato de própolis na dieta de cães, para avaliar possíveis efeitos na condição corporal, parâmentros sanguíneos e características fecais. Desta forma, o objetivo foi avaliar os efeitos da inclusão de extrato própolis no alimento completo destinado a cães sobre a condição corporal, parâmetros sanguíneos, resposta vacinal e escore fecal.

\section{MATERIAL E METODOS}

O experimento foi aprovado pela Comissão de Ética ao Uso de Animais, protocolo n.027/2011, do Setor de Ciências Agrárias da Universidade Federal do Paraná em 14 de outubro de 2011.

A preparação do extrato, o teor de flavonoides totais (TFT) em apigenina por meio de cromatografia líquida de alta resolução e a incorporação no óleo foram realizadas segundo protocolo adaptado de Franco e Bueno (1999). O teor de apigenina do 
extrato utilizado (SLNC206) incluídos a dieta foi de $0,79 \mathrm{mg} \mathrm{kg}^{-1}$ de ração. A Tabela 1 é referente à composição química da dieta utilizada como base neste experimento.

Tabela 1- Composição química analisada e calculada da dieta base

\begin{tabular}{lc}
\hline & Dieta controle $(\mathrm{g} / \mathrm{kg})$ \\
\hline Matéria seca & 888,0 \\
Proteína Bruta & 280,0 \\
Extrato etéreo em hidrólise ácida & 80,0 \\
Fibra bruta & 50,0 \\
Matéria mineral & 90,0 \\
Cálcio & 20,0 \\
Fósforo total & 8,0 \\
\hline EM (kcall $\mathrm{kg})^{1}$ & 2990,0 \\
\hline IEM: energia metabolizável estimada de acordo com NRC (2006); &
\end{tabular}

Foi utilizado um alimento completo para cães em crescimento respeitando as exigências nutricionais de acordo com NRC (2006) (Tabela 1). A dieta controle (DC) recebeu apenas 0 óleo de soja e a outra dieta recebeu o extrato de própolis (EP) diluído em óleo de soja numa concentração de $1,067 \mathrm{ml}$ $\mathrm{kg}^{-1}$ de ração. O teor de flavonoides totais em apigenina da dieta EP ficou em $3,97 \mathrm{mg} \mathrm{kg}^{-1}$ de ração.

Foram utilizados 16 cães da raça Beagle (oito fêmeas e oito machos) com 11 meses de idade $(10,12 \mathrm{~kg}+1,83)$, os quais foram alojados em baias de alvenaria com solário (1,5 $\mathrm{m}$ de largura por 2,0 m de comprimento).

O período experimental para avaliação da condição corporal foi de 20 semanas, as avaliações de peso, escore de condição corporal (ECC) e espessura do tecido adiposo em na sétima vértebra lombar (L7) foi realizado no início e final do experimento. O ECC foi realizado de acordo com Sharon (2003), variando de 1 a 5 (sendo 1 animais muito magros e 5 obesos). Para avaliar a espessura do tecido adiposo subcutâneo ( $\mathrm{mm}$ ) na vértebra $L 7$ foi realizado com ultrassom em plano transversal usando um transdutor linear de $7,5 \mathrm{MHz}$, proposto por Morooka et al. (2001).

Foram realizadas três coletas de sangue durante 0 experimento, no início, meio e final do período experimental para realização do hemograma e perfil lipídico. As coletas foram realizadas em jejum, pela venopunção da jugular externa. Cerca de $3 \mathrm{~mL}$ de sangue foram destinados à obtenção de soro e $1,5 \mathrm{~mL}$ para obtenção de plasma com o uso de EDTA a 10\%. As análises foram realizadas num tempo máximo de $72 \mathrm{~h}$ após a coleta. Foram avaliados números de hemácias e leucócitos, concentração de hemoglobina, hematócrito, contagem diferencial de leucócitos, concentração de proteína plasmática, colesterol total e TAG sérico.

Para determinação do hemograma foram utilizadas as técnicas de rotina descritas por Jain (1993). O hematócrito foi determinado pelo método do micro-hematócrito $e$ as concentrações de proteínas plasmáticas pelo método do refratômetro. O colesterol total e TAG foram analisados no aparelho BIOPLUS 2000. Foi usado o teste enzimático-colorimétrico com fator clareante de lipídeos para determinação quantitativa do colesterol total2 e TAG3 presente no soro.

Para análise de resposta vacinal foram realizadas quatro coletas de sangue com intervalos de 28 dias. Após a primeira e segunda coleta foi feito um desafio ao sistema imunológico com a aplicação de vacina óctupla (Recombitek C6/CV - Merial®) comercial para cães (contra cinomose, parvovirose, coronavirose, parainfluenza, adenovirose, hepatite infecciosa e leptospirose canina). As amostras de soro das quatro coletas foram armazenadas e congeladas.

Foi realizado a titulação de resposta vacinal para cinomose canina e os anticorpos contra o vírus da cinomose canina foram avaliados mediante inibição da hemaglutinação (HI). Inicialmente, as amostras de soro foram diluídas a 1:5 com tampão salina borato (BBS; $1.5 \mathrm{M} \mathrm{NaCl}, 0.5 \mathrm{M} \mathrm{H} 3 \mathrm{BO} 3$, 1.0M NaOH, pH 9.0). A seguir, foram tratadas para a remoção de inibidores 
inespecíficos de hemaglutinação e de aglutinação como descrito a seguir: ao mesmo volume de soro diluído foi adicionada uma suspensão de caulim a $25 \%$ em solução salina fosfatada (PBS; $\mathrm{pH} 7,2$ ) e incubado durante $30 \mathrm{~min}$ à temperatura ambiente, homogeneizando periodicamente. Após centrifugação a $400 \mathrm{rpm}$, durante $10 \mathrm{~min}, 0$ sobrenadante foi adsorvido em igual volume $(50 \mathrm{~mL})$ de hemácias de suínos diluídas a 50\% em tampão VAD, pH 6.0 $(0.15 \mathrm{M} \mathrm{NaCl}, 0.3 \mathrm{M}$ Na2HPO4, 0.15M $\mathrm{NaH} 2 \mathrm{PO} 4)$, durante $1 \mathrm{~h}$, a $4^{\circ} \mathrm{C}$. $\mathrm{O}$ sobrenadante foi coletado e estocado a $-20^{\circ} \mathrm{C}$ até $\mathrm{o}$ momento da realização do teste.

As amostras tratadas foram diluídas a partir de 1:20 até 20480 em microplacas com fundo em "V" usando tampão BABS (BBS com $0.2 \%$ de soro fetal bovino), incubadas com a amostra de vírus da cinomose canina (Cornell A7517 strain; quatro unidades hemaglutinantes $\mathrm{mL}^{-25}$ ) e após $2 \mathrm{~h}$ a $37^{\circ} \mathrm{C}$, foram adicionados $50 \mathrm{~mL}$ de uma suspensão de hemácias de suíno a $0,5 \%$ (em VAD, pH 6,0).

A leitura foi feita após incubação noturna a $4^{\circ} \mathrm{C}$. Os testes foram considerados válidos quando as hemácias dos poços controles haviam sedimentado totalmente e quando a titulação reversa confirmava as quatro unidades hemaglutinantes do vírus. Em todas as microplacas foram incluídas amostras negativas de soro e amostras com títulos de anticorpos conhecidos, como controles. Amostras de soro com título $<20$ foram consideradas negativas (CARMICHAEL; BINN, 1981).

As características das fezes foram avaliadas pelo escore fecal. $O$ escore foi avaliado diariamente durante todo o período experimental, atribuindose notas de 1 a 5 , sendo: 1 = fezes pastosas e sem forma; 2 = fezes macias e mal formadas; $3=$ fezes macias, formadas e úmidas; $4=$ fezes bem formadas e consistentes; 5 = fezes bem formadas, duras e secas (CARCIOFI et al. 2009).

Os animais foram distribuídos em delineamento inteiramente casualizado. Os dados de condição corporal, hemograma e parâmetros sanguíneos foram obtidos por meio das mensurações realizadas no início e final do período experimental (final - início). Os dados foram submetidos ao teste de normalidade e em seguida foi realizado o teste t-Student para os dados paramétricos e teste Kruskal-Wallis para os não paramétricos (escore fecal). Em ambos os testes foi considerado $\mathrm{P}<0,05$ como diferença significativa. As análises foram feitas utilizando 0 pacote estatística SAS (Statistical Analysis System, version 8,2; Inst, Inc., Cary, $\mathrm{NC)}$.

\section{RESULTADOS E DISCUSSÃO}

Há alguns componentes da própolis, como os flavonoides que são capazes de proporcionar vários efeitos benéficos, atuando como antioxidante, anti-inflamatório e de efeito vaso dilatador, ação antialérgica, ações antimicrobianas, entre outros (LOPES et al., 2000). Além disso, parecem promover a diminuição do peso corporal, gordura corporal e auxiliar na prevenção e tratamento da obesidade (LIN; LIN-SHIAU, 2006). Contudo, as pesquisas estão iniciando para avaliar esse produto na nutrição dos animais, inclusive na nutrição de cães. No presente estudo não foram identificados os flavonoides presentes no EP utilizado, mas de acordo com Marcucci et al. (1999) os principais flavonoides encontrados no EP são: campferol, quercetina, isorramnetina e a galangina.

$\mathrm{Na}$ Tabela 2 observamos os pesos dos animais no início e final do experimento de ambas as dietas, para os cães que receberam a DC não foi 
observado diferença entre o início e o final do experimento para o peso, L7 e escore $(P>0,05)$. Já para os cães que receberam a dieta EP observou redução do escore e de L7 ao final do período experimental $(P<0,05)$.

Tabela 2- Ingestão de alimento (g /cão/ dia) e variação (final-início) nas avaliações de condição corporal de cães alimentados com uma dieta controle (DC, sem extrato de própolis) e com a dieta EP $(1,067 \mathrm{ml}$ de extrato de própolis/kg de ração).

\begin{tabular}{lcccc}
\hline Tratamento & Ingestão $(\mathbf{g})$ & Peso $(\mathrm{Kg})$ & Escore $^{1}$ & $\mathrm{L7}^{2}$ \\
DC (Inicial -i) & - & 9,610 & 3,0 & 4,59 \\
DC (final - f) & - & 9,625 & 3,0 & 4,36 \\
P & - & 0,898 & 0,346 & 0,699 \\
\hline EP (i) & - & 10,217 & 3,8 & 4,58 \\
EP (f) & - & 9,880 & 3,0 & 3,21 \\
P & 269,89 & 0,721 & 0,048 & $<0,001$ \\
\hline DC (f-i) & 267,75 & 0,015 & 0,0 & $-0,231$ \\
EP (f-i) & 12,01 & 0,330 & $-0,875$ & $-1,372$ \\
EPM ${ }^{3}$ & 0,737 & 0,042 & - & 0,234 \\
PI & & 0,162 & 0,008
\end{tabular}

${ }^{1}$ Escore de condição corporal, escala de 1 (magro) a 5 (obeso);

${ }^{2}$ Avaliação feita com ultrassom na vértebra L7;

${ }^{3}$ EPM: erro padrão da média

${ }^{4}$ Diferenças significativas se $\mathrm{P}<0,05$ entre as médias pelo teste t-Student e mediana pelo teste Kruskal-Wallis (Escore).

Comparando as variações (finalinicial) das dietas observou-se que os animais que receberam a dieta com extrato de própolis (EP) apresentaram maior redução de $\mathrm{L} 7(\mathrm{~mm})$ e peso $(\mathrm{kg})$ do que a $D C(P<0,05)$. Enquanto para a ingestão (g) e ECC não houve variação durante o período experimental (Tabela 2).

O mecanismo pelo qual 0 flavonoide pode diminuir o percentual de gordura corporal ainda não está elucidado. Koya-Miyata et al. (2009) avaliaram o EP para camundongos machos (5 mg/kg e 50 mg/kg) e observaram resultados semelhantes a este estudo, reduzindo o ganho de peso de camundongos machos (50 mg/kg) e fêmeas $(25 \mathrm{mg} / \mathrm{kg})$.

Não foi observada diferença $(P>0,05)$ entre as dietas nos valores de hemograma (Tabela 3). Foram observadas diferenças $(P<0,05)$ nos valores de colesterol total dos animais no início e final do experimento de ambas as dietas (Tabela 4). Além disso, ao avaliar a variação (final-inicial) do colesterol total, a dieta EP apresentou a maior redução ( $P>0,05$, Tab. 4). Segundo Koya-Miyata et al. (2009) a própolis é capaz de reduzir os níveis séricos de triglicerídeos, colesterol, gordura não esterificada e triglicerídeos no fígado. Os autores afirmam que os resultados sugerem que os mecanismos da inibição de acúmulo de tecido adiposo visceral sejam pela regulação negativa da síntese de ácidos graxos. Assim como os resultados apresentados no presente estudo, a redução na espessura de tecido adiposo subcutâneo da região lombar dos cães pode ter ocorrido pela alteração no metabolismo lipídico, já que estes apresentaram maior redução na concentração de colesterol total sanguíneo.

Tabela 3- Valores de hemograma e análises bioquímicas séricos para fosfatase alcalina, creatinina, de cães alimentados com dietas suplementadas (EP) ou não (DC) com extrato de própolis.

\begin{tabular}{|c|c|c|c|c|c|}
\hline \multirow{2}{*}{ Parâmetros sanguíneos } & \multirow{2}{*}{$\mathrm{VR}^{1}$} & \multicolumn{2}{|c|}{ Dietas } & \multirow{2}{*}{$P^{2}$} & \multirow{2}{*}{$\mathrm{EPM}^{3}$} \\
\hline & & $D C$ & EP & & \\
\hline 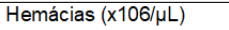 & $5,5-8,5$ & 5,65 & 5,97 & 0,97 & 0,092 \\
\hline Hemoglobina $(\mathrm{g} / \mathrm{dL})$ & $12,0-18,0$ & 15,33 & 15,60 & 0,64 & 0,260 \\
\hline Hematócrito (\%) & $37,0-55,0$ & 42,92 & 45,21 & 0,15 & 0,615 \\
\hline Leucócitos totais $(/ \mu \mathrm{L})$ & $6000-17000$ & 9341,7 & 9320,8 & 0,23 & 460,4 \\
\hline Neutrófilos $(/ \mu \mathrm{L})$ & $3000-11500$ & 5643,5 & 6084,9 & 0,07 & 342,1 \\
\hline Eosinófilos $(/ \mu \mathrm{L})$ & $100-1250$ & 182,00 & 270,00 & 0,47 & 58,20 \\
\hline Linfócitos $(/ \mu \mathrm{L})$ & $1000-4800$ & 2786 & 2468 & 0,93 & 154,0 \\
\hline 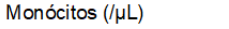 & $150-1350$ & 721,00 & 516,00 & 0,47 & 70,11 \\
\hline PPT (g/DI) & $6,0-8,0$ & 6,44 & 6,66 & 0,24 & 0,092 \\
\hline $\mathrm{FA}(\mathrm{UI} / \mathrm{L})$ & $20-156$ & 58,7 & 50,7 & 0,58 & 5,441 \\
\hline Creatinina (mg/dL) & $0,5-1,5$ & 0,6 & 0,6 & 0,84 & 0,048 \\
\hline
\end{tabular}

1VR: valores de referência; ${ }^{2}$ Médias comparadas pelo Teste t-Student $(\mathrm{P}>0,05)$; ${ }^{3}$ EPM: erro padrão da média; ${ }^{4} \mathrm{PPT}$ : proteína plasmática total; FA: Fosfatase Alcalina. 
Tabela 4- Colesterol total (mg/dL) e triacilglicerol (mg/dL) inicial (i), final (f) e Final - inicial $(f-i)$ de cães alimentados com uma dieta controle (DC, sem extrato de própolis) e com a dieta EP4 $(1,067 \mathrm{ml}$ de extrato de própolis/kg de ração).

\begin{tabular}{|c|c|c|}
\hline Tratamento & Colesterol total $(\mathrm{mg} / \mathrm{dL})$ & Triacilglicerol (mg/dL) \\
\hline DC (Inicial - i) & 67,61 & 112,75 \\
\hline$D C($ final $-f)$ & 51,67 & 74,77 \\
\hline $\mathrm{P}^{1}$ & 0,007 & 0,104 \\
\hline EP (i) & 78,71 & 107,22 \\
\hline$E P(f)$ & 53,45 & 75,04 \\
\hline$P^{1}$ & $<0,001$ & 0,004 \\
\hline$D C(f-i)$ & $-15,94$ & $-37,98$ \\
\hline$E P(f-i)$ & $-25,16$ & $-32,18$ \\
\hline $\mathrm{EPM}^{2}$ & 2,81 & 11,24 \\
\hline$P^{1}$ & $<0,001$ & 0,102 \\
\hline
\end{tabular}

${ }^{1}$ Médias comparadas pelo Teste t-Student $(\mathrm{P}>0,05)$; ${ }^{2} \mathrm{EPM}$ : erro padrão da média

Assim como a própolis, o chá verde possui alta quantidade de flavonoides, principalmente catequinas, capazes de promover a diminuição do peso, gordura corporal e auxiliar na prevenção e tratamento da obesidade e de doenças associadas como diabetes. Em experimento com humanos, Nagao et al. (2005) obtiveram melhora do perfil lipídico, diminuindo a concentração de colesterol total, lipoproteína de baixa densidade (LDL) e TAG. Ashida et al. (2004) ofereceram a ratos chá verde ao invés de água por três semanas e o chá verde reduziu o peso do tecido adiposo sem qualquer mudança no peso corporal e consumo alimentar. Também foram reduzidas significativamente as concentrações sanguíneas de colesterol total e ácidos graxos livres.

No presente estudo não foram observadas diferenças significativas para os outros parâmetros sanguíneos avaliados, no entanto tais parâmetros se encontravam dentro dos valores de referência para a espécie. Resultados semelhantes foram encontrados por Turner et al. (2006), os quais avaliaram o fornecimento do EP por 42 dias, para cavalos e eles observaram que os valores de hematócrito, hemoglobina, número de linfócitos e concentração sérica de lactato não foram alterados.

De acordo com o descrito por Arauco et al. (2007), os valores médios das porcentagens de linfócitos, neutrófilos, eosinófilos e basófilos do sangue periférico de girinos de rã-touro não foram influenciados pelos diferentes níveis de própolis na ração $(0,0 ; 0,2$; 0,$5 ; 1$ e 1,5\%). Os autores somente observaram diferença na porcentagem de monócitos, no qual os girinos que receberam o extrato hidroalcoólico de própolis a $1,5 \%$ e aqueles que não receberam, apresentaram a menor porcentagem desse grupo leucocitário no sangue.

Em relação à resposta vacinal, não foram observadas diferenças contra o vírus da cinomose canina entre os tratamentos ( $P>0,05$, Figura 1). Em um estudo feito por Kong et al. (2004) ao fornecerem doses de polissacarídeos de própolis via subcutânea por três dias, foram observados efeitos sobre a resposta vacinal contra o vírus de Newcastle apenas na maior dose utilizada $(1 \mathrm{mg})$ somente aos 21 e 28 dias pós-vacinais. Ferreira et al. (2008) usaram própolis marrom como adjuvante para aumentar a resposta vacinal contra o vírus da cinomose canina. Os grupos de camundongos que receberam as concentrações mais altas da vacina $(1,5 \times 106$ e $3 \times 106$ TCDI50) acrescidas de $400 \mu \mathrm{g}$ de própolis apresentaram incremento significativo na resposta imune humoral quando comparados aos grupos que receberam as mesmas doses da vacina sem própolis. Este efeito na melhora da resposta vacinal encontrado na literatura pode não ter sido demonstrado no presente estudo pela diferença na via de administração do EP e pelo mesmo ter passado pelo trato digestório podendo ocasionalmente ter alterado sua função imuno estimulante. 


\section{REFERENCIAS}

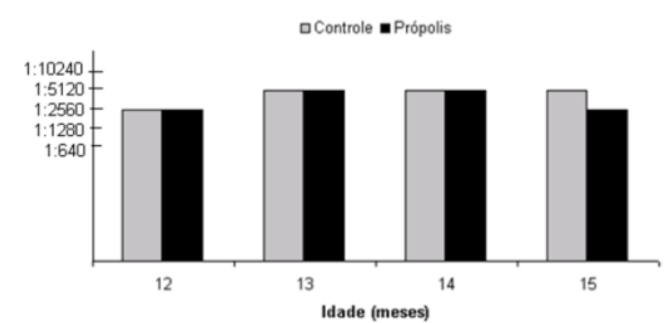

Figura 1- Nível de diluição que apresentou hemaglutinação em cães da raça Beagle aos 12, 13, 14 e 15 meses de idade alimentados com dietas suplementadas ou não com extrato de própolis.

Em relação às características das fezes, a inclusão do extrato de própolis não influenciou o escore fecal e este permaneceu 4 para os dois grupos. Esta avaliação é importante e muito levada em consideração pelos tutores dos cães, desta forma sempre que um ingrediente é avaliado, necessita-se avaliar também o escore das fezes.

As propriedades da própolis estão diretamente relacionadas à sua composição química, o que se constitui no principal desafio para o seu uso em fitoterapia, tendo em vista que a sua composição varia de acordo com a vegetação da região, a época da coleta e a técnica empregada, bem como em função da espécie da abelha e do grau de africanização da Apis mellifera no Brasil, fatores importantes na definição das suas propriedades físicas, químicas e biológicas (PEREIRA et al., 2002).

\section{CONCLUSÕES}

A inclusão de extrato de própolis a dieta de animais jovens por cinco meses estimulou a redução de peso, de tecido adiposo subcutâneo lombar dos cães e redução do teor de colesterol total. Enquanto que não houve influência na resposta vacinal, contra o vírus cinomose, além de não alterar as características fecais.
ARAUCO, L.R.R.; STÉFANI, M.V.; NAKAGHI, L.S.O. Efeito do extrato hidroalcoólico de própolis no desempenho e na composição leucocitária do sangue de girinos de rãtouro (Rana catesbeiana). Acta Scietiarum. Animal Sciences, v.29, n.1, p.227-234, 2007.

ASHIDA, H.; FURUYASHIKI, T.; NAGAYASU, H.; BESSHO, H.; SAKAKIBARA, H.; HASHIMOTO, T.; KANAZAWA, K. Anti-obesity actions of green tea: Possible involvements in modulation of the glucose uptake system and suppression of the adipogenesisrelated transcription factors. BioFactors, v.22, n.1-4, p.135-140, 2004.

BORGES, F.M.O. Programas de redução de peso para cães e gatos. In: Simpósio Sobre Nutrição De Animais De Estimação, 2004, Campinas. Anais... Colégio Brasileiro de Nutrição Animal, 2004, p.1-48.

CARCIOFI, A.C.; DE-OLIVEIRA, L.D.; VALÉRIO, A.G.; BORGES, L.L.; DE CARVALHO, F.M.; BRUNETTO, M.A.; VASCONCELLOS, R.S. Comparison of micronized whole soybeans to common protein sources in dry dog and cat diets. Animal Feed Science and Technology, v.151, n.3- 4, p.251-260, 2009.

CARMICHAEL, L.E.; BINN, L.N. New enteric viruses in the dog. Advances in Veterinary Science and Comparative Medicine, v.25, n.1, p.1-37, 1981.

FERREIRA, L.N.; FONSECA, P.F.; CAETANO, C.F.; SIEDLER, B.S.; MUNHOZ, L.S.; VILELA, C.O.; FISCHER, G.; VARGAS, G.D.; VIDOR, T. I. Efeito adjuvante da própolis marrom em vacina viva com antígenos múltiplos. In: Congresso Brasileiro De Medicina Veterinária, 2008, Gramado. Anais... Conbravet, 2008. CD-ROM. 
FRANCO, S.L.; BUENO, J.H.F. Otimização de processo extrativo de própolis.

Infarma-Ciências

Farmacêuticas, v.11, n.11, p.48-51, 1999.

JAIN, N.C. 1993. Essentials of veterinary hematology. Philadelphia: Lea \& Febiger, 1993, $417 \mathrm{p}$.

KONG, X.; HU, Y.; RUI, R.; WANG, D.; $\mathrm{LI}, \mathrm{X}$. Effects of Chinese herbal medicinal ingredients on peripheral lymphocyte proliferation and serum antibody titer after vaccination in chicken. International Immunopharmacology, v.4, n.7, p.975-982, 2004.

KOYA-MIYATA, S.; ARAI, N.; MIZOTE, A.; TANIGUCHI, Y.; USHIO, S.; IWAKI, K.; FUKUDA, S. Própolis prevents dietinduced hyperlipidemia and mitigates weight gain in diet-induced obesity in mice. Biological \& Pharmaceutical Bulletin, v.32, n.12, p. 2022-2028, 2009.

LAFLAMME, D.P.; HUME, E.; HARRISON, J. Evaluation of zoometric measures as an assessment of body composition of dogs and cats. In: Ralston Purina Co. St. Louis, 1998, St. Louis. Anais... St Louis: Nestlé-Purina, 1998.

LIN, J.K.; LIN-SHIAU, S.Y. Mechanisms of hypolipidemic and anti-obesity effects of tea and tea polyphenols. Molecular Nutrition \& Food Research, v.50, n.2, p.211-217, 2006.

LOPES, R.M.; OLIVEIRA, T.D.; NAGEM, T.J.; PINTO, A.D.S. Flavonoides. Biotecnologia, Ciência \& Desenvolvimento, v.3, n.14, p.18-22, 2000.

MARCUCCI, M.C. Composição química e atividade biológica. Revista da Universidade de Franca, v.1, n.7, p.17, 1999.
MOROOKA, T.; NIIYAMA, M.; UCHIDA, E.; UEMURA, M.; MIYOSHI, K.; SAITO, $M$. Measurement of the back fat layer in Beagles for estimation of obesity using two-dimensional ultrasonography. Journal of Small Animal Practice, v.2, n.42, p.56-59, 2001.

MORALES, W.F. Evidencia científica del propoleos desde el punto de vista médico. In: Congresso Internacional De Propoleo., 2000, Buenos Aires. Anais... Buenos Aires: Proapi, 2000, p.21-31.

NAGAO, T; KOMINE, Y.; SOGA, S.; MEGURO, S.; HASE, T.; TANAKA, Y.; TOKIMITSU, I. Ingestion of a tea rich in catechins leads to a reduction in body fat and malondialdehyde-modified LDL in men. American Journal of Clinical Nutrition, v.81, n.1, p.122-129, 2005.

National Research Council, 2006. Nutrient Requirements of Dogs and Cats. NRC, Natl. Acad. Press,Washington, DC, USA, 2006. 424 p.

PEREIRA, A.S.; SEIXAS, F.R.M.S.; AQUINO NETO, F.R. Própolis: 100 anos de pesquisa e suas perspectivas futuras. Química Nova, v.25, n.2, p.321-326, 2002.

SPECK, L.M. Compendium of methods for the microbiological examination of foods, D.C.: American Public Health Association., 1984. 700 p.

SHARON, A. Clinical weight management for dogs and cats. In: Wsava-Congress Of The World Small Animal Veterinary Association, 2003, Bangkok. Anais... Bangkok: WSAVA, 2003, p.56-69.

TURNER, K.K.; NIELSEN, B.D.; O'CONNOR, C.I.; Burton, J.L. Bee pollen product supplementation to horses in training seems to improve feed intake: a 
pilot study. Journal of Animal Physiology and Animal Nutrition, v.90, n.9, p.414-420, 2006.

UZEL, A.; ÖNÇAĞ, Ö.; ÇOĞULU, D. \& GENÇAY, Ö. Chemical compositions and antimicrobial activities of four different Anatolian propolis samples. Microbiology Research, v.160, n.1, p.189-195, 2005. 